\title{
Efficacy of benralizumab for patients with severe eosinophilic asthma: a retrospective, real-life study
}

Takanori Numata $^{*+}$ D , Hanae Miyagawa ${ }^{\dagger}$, Saiko Nishioka, Keitaro Okuda, Hirofumi Utsumi, Mitsuo Hashimoto, Shunsuke Minagawa, Takeo Ishikawa, Hiromichi Hara, Jun Araya and Kazuyoshi Kuwano

\begin{abstract}
Background: Benralizumab, an anti-interleukin-5 (IL-5) receptor a monoclonal antibody, significantly reduces the number of annual exacerbations and oral corticosteroid (OCS) maintenance doses for patients with severe eosinophilic asthma (SEA). However, few studies on the efficacy of this biologic in real life are available. The aim was to elucidate the efficacy of benralizumab by evaluating changes in clinical parameters after benralizumab treatment in patients with SEA.
\end{abstract}

Methods: From July 2018 to December 2019, 24 Japanese patients with SEA received benralizumab at Jikei University Hospital. We retrospectively evaluated the patients' characteristics, parameters, numbers of exacerbations and maintenance OCS doses.

Results: Among the 24 patients, eleven patients had received mepolizumab treatment and were directly switched to benralizumab. The peripheral blood eosinophil and basophil counts significantly decreased after benralizumab treatment regardless of previous mepolizumab treatment. Pulmonary function, Asthma Control Test scores, the numbers of annual exacerbations and maintenance OCS doses in patients without previous mepolizumab treatment tended to improve without significant differences. Fourteen patients (58\%) were responders according to the Global Evaluation of Treatment Effectiveness (GETE) score. The proportion of GETE responders among patients with aspirin-exacerbated respiratory disease (AERD) tended to be lower than that among patients without AERD $(p=0.085)$. After benralizumab treatment, the change in the forced expiratory volume in $1 \mathrm{~s}$ from baseline was 200 $\mathrm{ml}$ or greater in eight patients (33\%), including three patients who were switched from mepolizumab.

Conclusion: Benralizumab treatment improved and controlled asthma symptoms based on the GETE score.

Keywords: Eosinophilic asthma, Benralizumab, Eosinophilic chronic rhinosinusitis, Global evaluation of treatment effectiveness

\footnotetext{
* Correspondence: t-numata@jikei.ac.jp

${ }^{\dagger}$ Takanori Numata and Hanae Miyagawa contributed equally to this work. Division of Respiratory Diseases, Department of Internal Medicine, The Jikei University School of Medicine, 3-25-8, Nishi-Shimbashi, Minato-ku, Tokyo 105-8461, Japan
}

C C The Author(s). 2020 Open Access This article is licensed under a Creative Commons Attribution 4.0 International License, which permits use, sharing, adaptation, distribution and reproduction in any medium or format, as long as you give appropriate credit to the original author(s) and the source, provide a link to the Creative Commons licence, and indicate if changes were made. The images or other third party material in this article are included in the article's Creative Commons. licence, unless indicated otherwise in a credit line to the material. If material is not included in the article's Creative Commons licence and your intended use is not permitted by statutory regulation or exceeds the permitted use, you will need to obtain permission directly from the copyright holder. To view a copy of this licence, visit http://creativecommons.org/licenses/by/4.0/ The Creative Commons Public Domain Dedication waiver (http://creativecommons.org/publicdomain/zero/1.0/) applies to the data made available in this article, unless otherwise stated in a credit line to the data. 


\section{Background}

Bronchial asthma is a common and chronic respiratory disease affecting 300 million people worldwide [1]. The prevalence of severe or difficult-to-treat asthma is approximately $3-10 \%$ [2, 3]. Severe and uncontrolled asthma has been reported to be associated with diminished health-related quality of life and high healthcare costs $[4,5]$.

The anti-interleukin-5 receptor $\alpha$ (IL-5RA) antibody benralizumab exerts antibody-dependent cell-mediated cytotoxicity (ADCC), the process by which natural killer cells cause eosinophil apoptosis, with rapid and nearly complete depletion in the peripheral blood. Benralizumab has been demonstrated to be an effective therapy for patients with severe eosinophilic asthma (SEA) as it reduces annual exacerbation rates and maintenance oral corticosteroid (OCS) doses and improves pulmonary function [6-9]. Although mepolizumab, an anti-IL-5 monoclonal antibody, has shown clinical efficacy for patients with SEA in Japan $[10,11]$, little evidence is available regarding benralizumab therapy for patients with severe asthma [12].

We therefore conducted this single-center retrospective study to elucidate the efficacy of benralizumab in a real-life setting.

\section{Methods}

\section{Subjects}

From July 2018 to December 2019, 24 Japanese patients with SEA received benralizumab injections (30 mg every 4 weeks for the first three injections and every 8 weeks for the subsequent injections) at Jikei University Hospital, Tokyo, Japan. All asthma patients were diagnosed by respiratory physicians based on Japanese guidelines [13] or the Global Initiative of Asthma (GINA) guidelines [4]. Severe asthma was defined as requiring a high dose of inhaled corticosteroids (ICSs) plus at least one of the following additional control measures: long-acting $\beta$ 2 agonists (LABAs), long-acting muscarinic antagonists (LAMAs), leukotriene receptor antagonists (LTRAs), a xanthine derivative and a daily OCS $[3,4,13]$. Xanthine derivatives are routinely prescribed in Japan because the Japanese guideline for the treatment of adult asthma recommends the use of xanthine derivatives in the setting of insufficient control with conventional control measures. SEA was defined as severe asthma with eosinophilic airway inflammation, which was defined as a peripheral blood eosinophil count $\geq 300 / \mu \mathrm{l}$.

The present study was approved by the Ethics Committee of Jikei University [30-319 (9340)]. Based on the ethical guidelines of Jikei University, informed consent was not necessary for this retrospective study, and we performed opt-out consent on the website of our hospital. The benralizumab prescription rule was based on the Pharmaceuticals and Medical Devices Agency in Japan. The inclusion criteria for initiating benralizumab treatment in patients were as follows: 1 . the patient had at least two exacerbations requiring OCS treatment in the previous year or before the introduction of mepolizumab; 2. if the patient did not receive mepolizumab treatment, the patient's blood eosinophil count was at least $150 / \mu \mathrm{l}$ at baseline or $\geq 300 / \mu \mathrm{l}$ in the previous year; or 3 . the patient received OCS maintenance therapy or another biologic (omalizumab or mepolizumab) regardless of the number of exacerbations or the blood eosinophil count.

\section{Data collection and evaluation}

We retrospectively examined the following characteristics: sex, age, comorbidities of eosinophilic diseases, smoking status, body mass index (BMI), baseline treatments including biologics, and the duration of asthma. We examined and evaluated the following parameters at baseline and at the final follow-up after 4 months: peripheral blood eosinophil and basophil counts, serum IgE, fractional exhaled nitric oxide (FeNO), the Asthma Control Test (ACT) score, pulmonary function test results [the forced vital capacity (FVC), forced expiratory volume in $1 \mathrm{~s}\left(\mathrm{FEV}_{1}\right), \mathrm{FEV}_{1} / \mathrm{FVC}, \% \mathrm{FEV}_{1}$ and \% peak expiratory flow (\%PEF)], and daily OCS maintenance doses as prednisone equivalents (mg). A change of $200 \mathrm{ml}$ or greater was adopted as a significant change in the $\mathrm{FEV}_{1}$ [12, 14-16]. The FeNO level was measured using a NIOX VERO ${ }^{\mathrm{sm}}$ device (Aerocrine AB, Stockholm, Sweden) with a $50 \mathrm{ml} / \mathrm{s}$ flow rate according to the American Thoracic Society/European Respiratory Society recommendations [17]. The number of annual exacerbations of asthma symptoms requiring systemic CS was defined as the total number of exacerbations $\times 12$ / the total duration of the observation period (months). Furthermore, we evaluated changes from baseline in these parameters. To evaluate clinical efficacy, we utilized the ACT score and the Global Evaluation of Treatment Effectiveness (GETE) score; the ACT score is clinically useful as a simple scoring system, and scores of 20-25 are classified as well-controlled asthma [4]. The minimal clinically important difference (MCID) was an ACT score of three points [18]. The GETE score was evaluated based on symptom severity, medication use and pulmonary function tests at the final follow-up after at least 4 months of benralizumab treatment [19]. The GETE score has five classifications: excellent, good, moderate, poor and worsening. A responder is defined as a patient with a good/excellent response when treated with benralizumab. The GETE score after mepolizumab treatment was used if the overall evaluation did not change for the patients switched from mepolizumab. 
The primary endpoint was the GETE score. We performed a subgroup analysis based on previous mepolizumab treatment with eosinophilic chronic rhinosinusitis (ECRS) or chronic rhinosinusitis with nasal polyps (CRSwNP) and with aspirin-exacerbated respiratory disease (AERD) because these factors affect the evaluation of clinical efficacy. The secondary endpoints included each parameter, each biomarker, changes in the number of asthma exacerbations and in daily CS doses, and the proportion of patients with a change in $\mathrm{FEV}_{1}$ from baseline $(\geq 200 \mathrm{ml})$. To examine sinusitis symptoms and findings, we utilized nasal discharge, nasal congestion and olfactory loss reported in the medical records.

\section{Statistical analyses}

All statistical analyses were performed using StatView version 5 (SAS Institute, Inc., Cary, NC, USA), and a post-hoc power analysis was performed with EZR (version 1.37, Saitama Medical Center, Jichi Medical University, Saitama, Japan) [20], which is a graphical user interface for R (version 3.4.1, The R Foundation for Statistical Computing, Vienna, Austria). All values are expressed as the mean \pm standard deviation (SD). A $p$ value $<0.05$ was considered statistically significant. To determine the characteristics of the responders, we statistically analyzed univariate models of patient characteristics, such as sex, age, BMI, peripheral blood eosinophil and basophil counts, previous mepolizumab treatment, and comorbidities. The factors associated with patient characteristics were analyzed using the Mann-Whitney $U$ test, Fisher's exact test, or the Wilcoxon signed-rank test (univariate model). Because the number of patients in the present study was small, we re-evaluated the clinical parameters, the percentage change in the number of annual exacerbations and maintenance CS doses with a post hoc power analysis $(\alpha$-error $<0.05$, cut-off 0.80$)$. Furthermore, logistic regression analysis was performed to evaluate the identified characteristics of the responders (multivariate model), including the peripheral blood eosinophil count $(\geq 300 / \mu \mathrm{l})$, ECRS or CRSwNP [11] as a comorbidity and other variables that achieved $p<0.20$ in the univariate model.

\section{Results}

\section{Patient characteristics}

Nine men and 15 women received benralizumab treatment with eight doses (median). The characteristics of the 24 patients are shown in Table 1. Among them, 11 had directly switched to benralizumab from mepolizumab treatment based on asthma symptoms $(n=2)$, the interval between hospital visits $(n=6)$ and discussions with physicians $(n=3)$ (Additional file 1). No significant differences in patient characteristics were found between the patients with and without previous mepolizumab treatment except for eosinophilic otitis media, which was frequently present in patients with previous mepolizumab treatment. In addition, we assessed the patients' characteristics in the following subgroups (Additional file 2): males, females, AERD (-) and AERD (+). We showed that the $\% \mathrm{FEV}_{1}, \% \mathrm{PEF}$ and $\mathrm{ACT}$ score were significantly lower in males than in females using posthoc power analysis. In addition, the AERD $(+)$ group showed significantly lower ACT scores and tended to have a lower $\% \mathrm{FEV}_{1}$ at baseline than the AERD (-) group (Additional file 2).

\section{Clinical efficacy}

The changes in clinical parameters and biomarkers are shown in Table 2. The peripheral blood eosinophil and basophil counts significantly decreased. However, no significant differences in the changes in pulmonary function, FeNO, the ACT score, the number of annual exacerbations or maintenance CS doses from baseline were found between all patients or in the presence or absence of previous mepolizumab treatment. The \%FVC, $\% \mathrm{FEV}_{1}$ and $\mathrm{FEV}_{1}$ were reevaluated using post-hoc power analysis, and no significant difference was found before and after benralizumab treatment regardless of previous mepolizumab treatment. The ACT score tended to increase in all patients $(n=24)$ and in the group without previous mepolizumab $(n=13)$ treatment without significant differences (Table 2). Furthermore, the total number of patients with a final ACT score $=25$ (wellcontrolled asthma) or an ACT score increase $\geq 3$ (significant change) was 11 (85\%) among the patients without previous mepolizumab treatment $(n=13)$ (data not shown). We determined the \% $\mathrm{FEV}_{1}$ and ACT score before and after benralizumab treatment in the AERD (-) and $(+)$ groups (Additional file 3 ). Although the $\% \mathrm{FEV}_{1}$ tended to improve in the AERD (-) group, no significant difference in the $\% \mathrm{FEV}_{1}$ was observed before and after benralizumab treatment in the AERD (+) group.

We show the GETE scores of all patients, the previous mepolizumab treatment $(-) /(+)$ groups and the AERD $(-) /(+)$ groups in Fig. 1. The total responder rate to benralizumab treatment was 58\% (14 patients), including good and excellent responses. Regardless of previous mepolizumab treatment, the response rate was approximately $60 \%$. The response rate in the AERD (-) group was higher than that in the AERD (+) group [71\% (12/ $17)$ vs $29 \%(2 / 7), p=0.085]$.

We compared baseline clinical parameters and comorbidities between the responders and nonresponders to benralizumab treatment (Table 3). A significant difference in the \%FVC at baseline was found between these two groups. No significant differences in clinical parameters at baseline were observed between the responders 
Table 1 Patient characteristics at baseline $(n=24)$

\begin{tabular}{|c|c|c|c|c|}
\hline & all patients $(n=24)$ & $\begin{array}{l}\text { previous mepolizumab } \\
\text { treatment }(-)(n=13)\end{array}$ & $\begin{array}{l}\text { previous mepolizumab } \\
\text { treatment }(+)(n=11)\end{array}$ & $\begin{array}{l}p \text { value between } \\
\text { two groups }\end{array}$ \\
\hline male, n (\%) & $9(38)$ & $4(31)$ & $5(45)$ & $0.68^{+}$ \\
\hline age (years), mean (SD) (range) & $57.5(13.4)(20-75)$ & $56.7(15.8)(20-75)$ & $58.4(10.6)(38-72)$ & $0.91^{\ddagger}$ \\
\hline disease duration, (years), mean (SD) (range) & $21.3(12.5)(4-54)$ & $21.2(14.2)(4-54)$ & $21.5(10.7)(8-36)$ & $0.68^{\ddagger}$ \\
\hline body mass index $\left(\mathrm{kg} / \mathrm{m}^{2}\right)$, mean (SD) & $23.4(4.8)$ & $24.6(5.1)$ & $21.9(4.1)$ & $0.19^{\ddagger}$ \\
\hline smoking (never/former), n & $18 / 6$ & $9 / 4$ & $9 / 2$ & $0.65^{\dagger}$ \\
\hline \multicolumn{5}{|l|}{ initial treatments use } \\
\hline 一ICS/LABA, n (\%) & $24(100)$ & $13(100)$ & $11(100)$ & - \\
\hline —ICS dose $(\mu \mathrm{g})$, mean $(S D)$, budesonide equivalent & $1381(448)$ & $1411(518)$ & $1345(370)$ & $0.66^{\ddagger}$ \\
\hline - LAMA, n (\%) & $14(58)$ & $7(54)$ & $7(64)$ & $0.70^{+}$ \\
\hline —LTRA, n (\%) & $20(83)$ & $11(85)$ & $9(82)$ & $>0.99^{\dagger}$ \\
\hline —xanthine derivative, n (\%) & $17(71)$ & $9(69)$ & $8(73)$ & $>0.99^{\dagger}$ \\
\hline —maintenance therapy of OCS, n (\%) & $8(33)$ & $6(46)$ & $2(18)$ & $0.21^{\dagger}$ \\
\hline —daily dose of OCS ${ }^{\mathrm{a}}(\mathrm{mg})$, mean (range) & $5.6(1.0-15)$ & $6.1(1.0-15)$ & $4.3(2.5-6)$ & $0.74^{\ddagger}$ \\
\hline \multicolumn{5}{|l|}{ comorbidities } \\
\hline -ECRS, n (\%) & $20(83)$ & $10(77)$ & $10(91)$ & $0.60^{\dagger}$ \\
\hline —EOM, n (\%) & $11(46)$ & $3(23)$ & $8(73)$ & $0.038^{\dagger}$ \\
\hline —AERD, n (\%) & $7(29)$ & $6(46)$ & $1(10)$ & $0.08^{\dagger}$ \\
\hline -EGPA, n (\%) & $4(17)$ & $1(8)$ & $3(27)^{b}$ & $0.30^{\dagger}$ \\
\hline —atopic dermatitis, n (\%) & $1(4)$ & $1(8)$ & $0(0)$ & $>0.99^{\dagger}$ \\
\hline \multicolumn{5}{|l|}{ previous biologics } \\
\hline —omalizumab, n (\%) / median (range) (month) & $5(21) / 11(3-88)$ & $1(8) / 3(3)$ & $4(40)$ / $15.5(4-88)$ & $0.14^{\dagger} / 0.16^{\ddagger}$ \\
\hline —mepolizumab, n (\%) / median (range) (month) & $11(46) / 21(5-35)$ & - & $11(100) / 21(5-35)$ & - \\
\hline —dupilumab, n (\%) / median (range) (month) & $1(4) / 6(6)$ & $1(8) / 6(6)$ & - & - \\
\hline number of benralizumab injections, median (range) & $8(2-11)$ & $8(2-10)$ & $7(4-11)$ & $0.98^{\ddagger}$ \\
\hline observation period (months), median (range) & $11.5(4-17)$ & $11(4-16)$ & $14(4-17)$ & $0.79^{\ddagger}$ \\
\hline
\end{tabular}

Data are presented as $\mathrm{n}(\%)$ or mean (standard deviation), unless otherwise stated

Abbreviations: SD standard deviation, ICS inhaled corticosteroid, LABA long-acting $\beta$-2 agonist, LAMA long-acting muscarinic antagonist, $L T R A$ leukotriene receptor antagonist, OCS oral corticosteroids, ECRS eosinophilic chronic rhinosinusitis, EOM eosinophilic otitis media, $A E R D$ aspirin-exacerbated respiratory disease, EGPA eosinophilic granulomatosis with polyangiitis

${ }^{\dagger}$ Fisher's exact test, ${ }^{\ddagger}$ Mann-Whitney $U$ test,

a prednisone equivalents dose

${ }^{\mathrm{b}}$ All three patients with EGPA received $100 \mathrm{mg}$ of mepolizumab injection

and nonresponders in the previous mepolizumab treatment $(-)$ and $(+)$ groups. To further examine the involvement of baseline clinical parameters in the efficacy of benralizumab, we analyzed changes in the $\mathrm{FEV}_{1}$ of $\geq 200 \mathrm{ml}$ and $<200 \mathrm{ml}$ (Table 3). The change in the $\mathrm{FEV}_{1}$ from baseline was $200 \mathrm{ml}$ or greater in eight patients (33\%), including three patients who were switched from mepolizumab treatment (Table 3). The \%FVC and $\% \mathrm{FEV}_{1}$ at baseline were significantly lower in patients with a change in the $\mathrm{FEV}_{1} \geq 200 \mathrm{ml}$ than in those with a change in the $\mathrm{FEV}_{1}<200 \mathrm{ml}$.

\section{Analysis of clinical characteristics using multivariate logistic regression}

We performed subgroup analyses using univariate logistic regression of the GETE score as follows: 1) patient characteristics and parameters, 2) with or without previous mepolizumab treatment, 3) with or without AERD as a comorbidity, and 4) with or without ECRS as a comorbidity (Table 4). Then, we selected the peripheral blood eosinophil count $(\geq 300 / \mu \mathrm{l})$, ECRS or CRSwNP, AERD, FeNO ( $\geq 50$ parts-per-billion) and BMI $(\geq 25 \mathrm{~kg} /$ $\mathrm{m}^{2}$ ) for multivariate logistic regression analysis of the GETE score. We found that the number of patients with AERD was significantly lower in the GETE responder group than in the non-responder group [odds ratio (OR) 0.035 , 95\% confidence interval $(\mathrm{CI})(0.002-0.72), p=$ 0.03] (Table 4).

\section{Others}

Four patients discontinued benralizumab treatment for the short term for the following reasons: adverse effects 


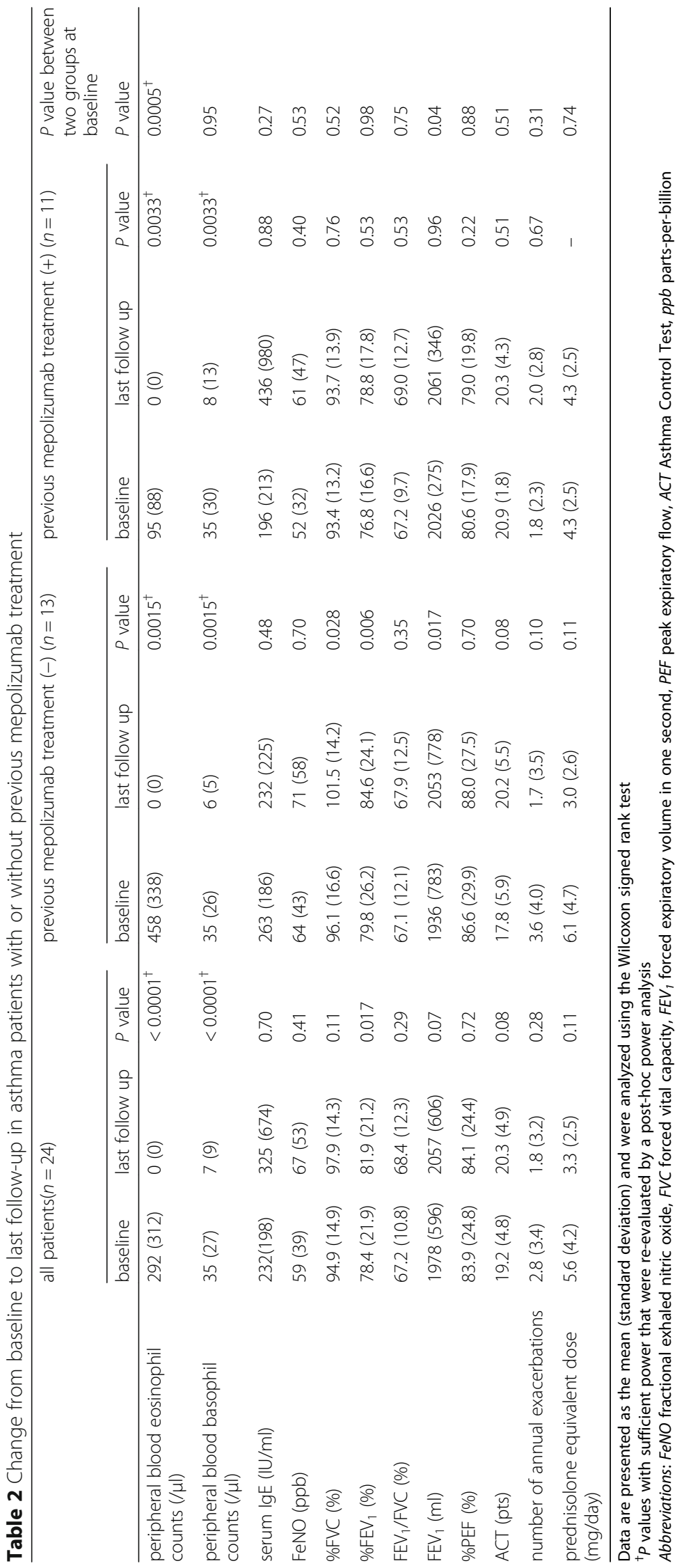




\section{GETE score}

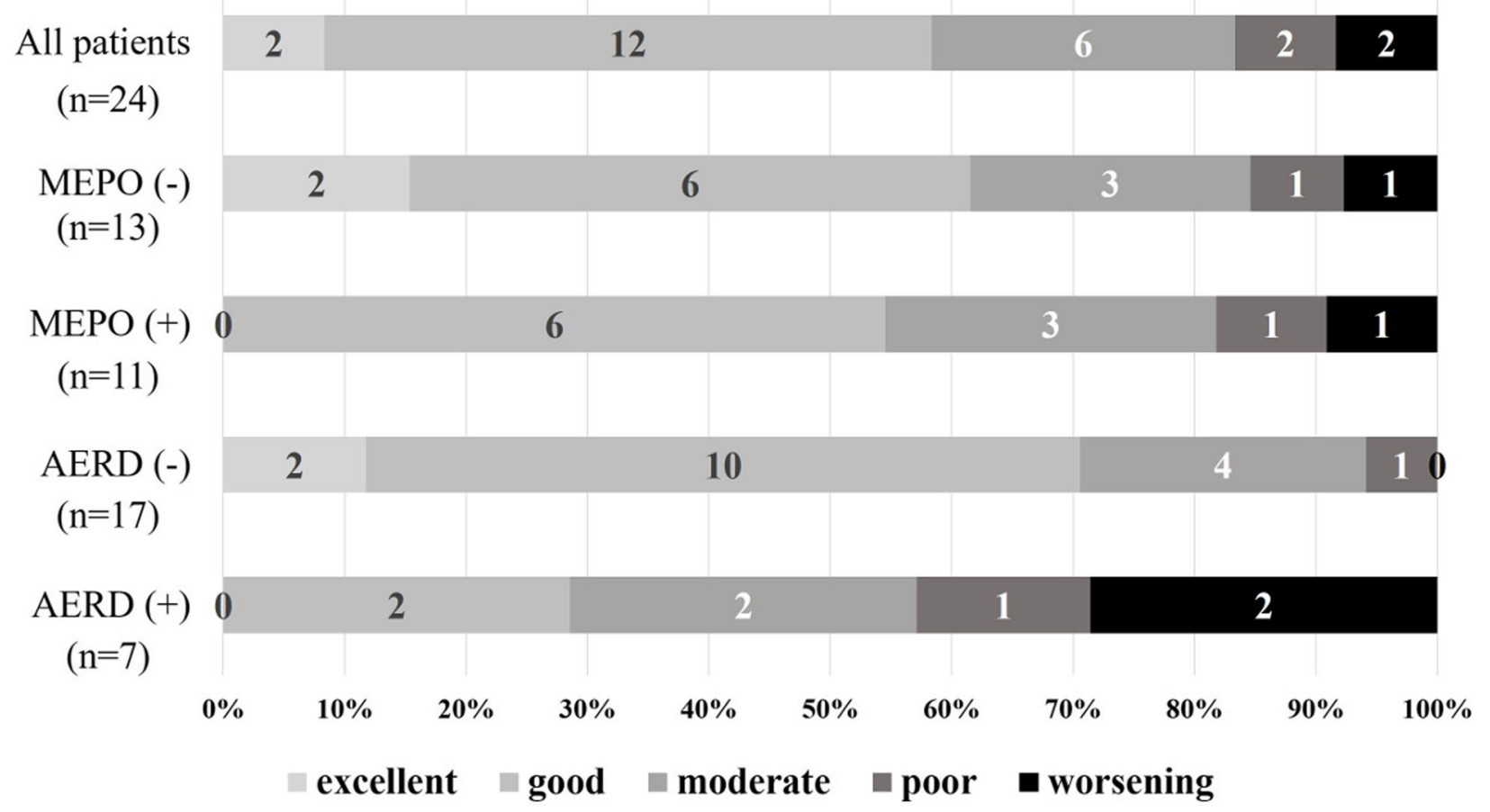

Fig. 1 GETE scores. The GETE scores for the following five settings: all patients ( $n=24$, 1st (upper)), without previous mepolizumab treatment $(n=13,2 n d)$, with previous mepolizumab treatment $(n=11$, 3rd), without AERD $(n=13,4$ th) and with AERD $(n=11$, 5th (bottom)). Except for the AERD group, the response rates to benralizumab were approximately 60-70\%. Abbreviations: GETE, Global Evaluation of Treatment Effectiveness, AERD, aspirin-exacerbated respiratory disease

[headache $(n=1)$ and injection site pain $(n=1)]$, poor effectiveness for asthma $(n=1)$ and other $(n=1)$ (data not shown).

We evaluated sinusitis symptoms in 18 of the 20 patients with comorbid SEA and ECRS. Based on patient symptoms in the medical records, nine patients $(50 \%)$ reported the efficacy of benralizumab treatment for sinusitis (data not shown).

\section{Discussion}

This retrospective, real-life benralizumab study showed that the response rate based on the GETE score was lower than the rate reported in real-life mepolizumab studies $[11,16]$. The number of annual exacerbations and maintenance CS doses tended to improve in patients without previous mepolizumab treatment. These parameters did not significantly decrease unlike those reported in major clinical trials and in Japanese subgroups $[6,8$, $9,12]$. These findings may be due to several reasons. First, real-life studies [11, 21, 22] generally enroll a relatively large number of patients with prior use of biologics compared to major RCTs $[6,8](13-33 \%$ vs $3-8 \%$ of patients). Hence, real-life studies may likely include a higher proportion of patients with treatmentrefractory asthma. Accordingly, we speculate that the lower response rate based on the GETE score can be attributed to a higher proportion of patients who needed to switch biologics in the present study. Intriguingly, however, $75 \%$ of the patients had maintained or improved asthma symptoms after changing to benralizumab in the present study, indicating the potential usefulness of benralizumab in the setting of switching biologics (Additional file 1).

Second, the proportion of all enrolled patients with AERD was approximately $30 \%$. In general, the prevalence of AERD is $7 \%$ in adult asthma populations and $15 \%$ in severe asthma populations [23]. In general, AERD is associated with weak pulmonary function and is also more likely to be associated with severe asthma [23]. Consistent with a previous retrospective study showing poor improvement of the $\mathrm{FEV}_{1}$ in patients with AERD after mepolizumab treatment [24], we showed no significant difference in the $\% \mathrm{FEV}_{1}$ before and after treatment in the AERD group. Third, we hypothesized that seasonal asthmatic exacerbations influenced the efficacy of benralizumab treatment. In the present 
Table 3 Patient characteristics based on the clinical efficacies

\begin{tabular}{|c|c|c|c|c|c|c|}
\hline at baseline & GETE $\geq \operatorname{good}(n=14)$ & GETE $\leq$ moderate $(n=10)$ & $p$ value & $\Delta \mathrm{FEV}_{1} \geq 200 \mathrm{ml}(n=8)$ & $\Delta \mathrm{FEV}_{1}<200 \mathrm{ml}(n=16)$ & $p$ value \\
\hline $\operatorname{sex}(M / F), n$ & $4 / 10$ & $5 / 5$ & 0.40 & $5 / 3$ & $4 / 12$ & 0.099 \\
\hline age (years) & $57.6(12.1)$ & $57.2(15.7)$ & 0.79 & $51.6(15.8)$ & $60.4(11.5)$ & 0.15 \\
\hline$-\operatorname{MEPO}(-)(n=13)$ & $56.9(12.6)(n=8)$ & $56.4(21.8)(n=5)$ & 0.71 & $52.8(19.4)(n=5)$ & $59.1(14.0)(n=8)$ & 0.51 \\
\hline -MEPO (+) $(n=11)$ & $58.7(12.6)(n=6)$ & $58.0(9.0)(n=5)$ & 0.85 & $49.7(10.2)(n=3)$ & $61.6(9.2)(n=8)$ & 0.098 \\
\hline BMI $\left(\mathrm{kg} / \mathrm{m}^{2}\right)$ & $22.0(4.2)$ & $25.3(5.1)$ & 0.09 & $24.7(5.5)$ & $22.7(4.4)$ & 0.46 \\
\hline$-\operatorname{MEPO}(-)(n=13)$ & $22.6(5.0)(n=8)$ & $27.7(3.8)(n=5)$ & 0.079 & $26.2(5.0)(n=5)$ & $23.5(5.3)(n=8)$ & 0.38 \\
\hline -MEPO (+) $(n=11)$ & $21.2(2.9)(n=6)$ & $22.8(5.4)(n=5)$ & 0.58 & $22.1(6.3)(n=3)$ & $21.8(3.5)(n=8)$ & 0.84 \\
\hline bEOS $(/ \mu l)$ & $306(216)$ & $271(426)$ & 0.20 & $407(424)$ & $234(234)$ & 0.27 \\
\hline -MEPO (-) (n=13) & $437(183)(n=8)$ & $492(531)(n=5)$ & 0.66 & $565(472)(n=5)$ & $391(236)(n=8)$ & 0.66 \\
\hline$-\mathrm{MEPO}(+)(n=11)$ & $132(104)(n=6)$ & $50(35)(n=5)$ & 0.20 & $143(127)(n=3)$ & $77(71)(n=8)$ & 0.31 \\
\hline bBASO $(/ \mu \mathrm{l})$ & $33(29)$ & $38(27)$ & 0.46 & $49(40)$ & $28(16)$ & 0.34 \\
\hline$-\operatorname{MEPO}(-)(n=13)$ & $28(18)(n=9)$ & $46(35)(n=5)$ & 0.38 & $41(37)(n=5)$ & $31(19)(n=8)$ & 0.77 \\
\hline$-\mathrm{MEPO}(+)(n=11)$ & $40(40)(n=6)$ & $29(13)(n=5)$ & 0.86 & $61(51)(n=3)$ & $26(13)(n=8)$ & 0.31 \\
\hline FeNO (ppb) & $70(42)$ & $41(26)$ & 0.08 & $70(39)$ & $53(38)$ & 0.26 \\
\hline$-\operatorname{MEPO}(-)(n=13)$ & $74(49)(n=8)$ & $47(30)(n=5)$ & 0.27 & $66(42)(n=5)$ & $63(48)(n=8)$ & 0.71 \\
\hline$-\mathrm{MEPO}(+)(n=10)^{\mathrm{a}}$ & $64(33)(n=6)$ & $33(22)(n=4)^{a}$ & 0.11 & $75(43)(n=3)$ & $42(23)(n=7)^{\mathrm{a}}$ & 0.25 \\
\hline \%FVC (\%) & $99.1(17.6)$ & $88.9(7.2)$ & $0.04^{+}$ & $83.8(9.9)$ & $100.4(14.0)$ & $0.005^{\dagger}$ \\
\hline$-\operatorname{MEPO}(-)(n=13)$ & $101.0(19.6)(n=8)$ & $88.3(5.9)(n=5)$ & $0.04^{\dagger}$ & $84.6(12.8)(n=5)$ & $103.3(15.1)(n=8)$ & 0.04 \\
\hline$-\operatorname{MEPO}(+)(n=11)$ & $96.7(15.9)(n=6)$ & $89.4(9.0)(n=5)$ & 0.47 & $82.3(3.2)(n=3)$ & $97.5(13.1)(n=8)$ & 0.07 \\
\hline$\% \mathrm{FEV}_{1}(\%)$ & $83.2(22.8)$ & $71.7(19.9)$ & 0.18 & $64.0(12.9)$ & $85.6(22.2)$ & $0.024^{\dagger}$ \\
\hline$-\operatorname{MEPO}(-)(n=13)$ & $86.2(20.6)(n=8)$ & $69.5(28.6)(n=5)$ & 0.38 & $60.5(14.3)(n=5)$ & $91.8(25.2)(n=8)$ & $0.028^{\dagger}$ \\
\hline -MEPO $(+)(n=11)$ & $79.1(13.1)(n=6)$ & $74.0(21.3)(n=5)$ & 0.47 & $69.7(9.5)(n=3)$ & $79.4(18.4)(n=8)$ & 0.41 \\
\hline \multicolumn{7}{|l|}{ comorbidities } \\
\hline — with AERD, n (\%) & $2(14)$ & $5(50)$ & 0.085 & $3(38)$ & $4(25)$ & 0.65 \\
\hline —with ECRS, n (\%) & $12(86)$ & $8(80)$ & $>0.99$ & $7(88)$ & $13(81)$ & $>0.99$ \\
\hline
\end{tabular}

Data at baseline are presented as mean (standard deviation), unless otherwise stated

$P$ value was analyzed using Fisher's exact test or Mann-Whitney $U$ test

Abbreviations: GETE global evaluation of treatment effectiveness, $\triangle F E V$, change from baseline to the last follow-up in the forced expiratory volume in $1 \mathrm{~s}, M E P O$ previous mepolizumab treatment, $B M I$ body mass index, $b E O S$ peripheral blood eosinophil count at baseline, $b B A S O$ peripheral basophil count at baseline, FeNO fractional exhaled nitric oxide, FVC forced vital capacity, FEV1 forced expiratory volume in $1 \mathrm{~s}$, AERD aspirin-exacerbated respiratory disease, ECRS eosinophilic chronic rhinosinusitis, $p p b$ parts-per-billion

${ }^{\dagger} P$ values with sufficient power that were re-evaluated by a post-hoc power analysis

adata missing $(n=1)$

study, only $50 \%$ of all patients received benralizumab treatment for 12 months or longer. Accordingly, seasonal variability may have led to these results [25]. Fourth, the efficacy of benralizumab might not differ from that of mepolizumab despite the complete disappearance of peripheral blood eosinophils. Several indirect meta-analyses have investigated these biologics, but the results are controversial [26-28].

The ACT score and $\% \mathrm{FEV}_{1}$ in the AERD group were lower than those in the AERD (-) group, and a significant difference in the GETE score was identified between the two groups. Few reports on the effectiveness of biologics in patients with AERD are available. A previous study reported that omalizumab displayed rapid clinical effectiveness and inhibited mast cell activation and leukotriene overproduction in AERD [29, 30]. Although mepolizumab treatment resulted in significant improvement of asthma and nasal symptoms in AERD in a retrospective study, the $\% \mathrm{FEV}_{1}$ did not improve [24]. To our knowledge, no similar results regarding benralizumab are available. The pooled analysis of RCTs demonstrated that nasal polyps were predictors of the response to benralizumab in SEA [7, 31]. However, clinical differences have also been reported to exist between patients with asthma and ECRS and those with AERD, such as differences in pulmonary function, the prevalence of OCS treatment and cytokine levels in nasal polyps [32, 33]. Furthermore, a previous report demonstrated that a functional polymorphism in IL5RA may contribute to eosinophil and mast cell activation along 
Table 4 Clinical characteristics in the GETE score using a univariate and multivariate logistic regression

\begin{tabular}{|c|c|c|c|c|c|c|}
\hline & $\begin{array}{l}\text { GETE } \geq \text { good } \\
(n=14)\end{array}$ & $\begin{array}{l}\text { GETE } \leq \text { moderate } \\
(n=10)\end{array}$ & odds ratio (95\%Cl) (univariate) & $p$ value & odds ratio (95\%Cl) (multivariate) & $p$ value \\
\hline sex (male), n (\%) & $4(29)$ & $5(50)$ & $0.40(0.07-2.2)$ & 0.29 & - & - \\
\hline age ( $\geq 65$ year-old), $n$ (\%) & $5(36)$ & $4(40)$ & $0.83(0.16-4.4)$ & 0.83 & - & - \\
\hline BMI $(\geq 25)\left(\mathrm{kg} / \mathrm{m}^{2}\right), \mathrm{n}(\%)$ & $3(21)$ & $5(50)$ & $0.27(0.05-1.6)$ & 0.15 & $0.1(0.004-2.8)$ & 0.18 \\
\hline bEOS $(\geq 300)(/ \mu \mathrm{l}), \mathrm{n}(\%)$ & $7(50)$ & $3(30)$ & $2.3(0.42-12.9)$ & 0.33 & $11.2(0.57-219)$ & 0.11 \\
\hline bBASO ( $\geq 40)(/ \mu l), n(\%)$ & $4(29)$ & $3(30)$ & $0.93(0.16-5.5)$ & 0.94 & - & - \\
\hline FeNO ( $\geq 50)(p p b), n(\%)$ & $9(64)$ & $3(30)$ & $3.6(0.62-21)$ & 0.15 & $3.7(0.24-57)$ & 0.35 \\
\hline MEPO (+), n (\%) & $6(43)$ & $5(50)$ & $0.75(0.15-3.8)$ & 0.73 & - & - \\
\hline \multicolumn{7}{|l|}{ comorbidities } \\
\hline —with AERD, n (\%) & $2(14)$ & $5(50)$ & $0.17(0.02-1.2)$ & 0.07 & $0.035(0.002-0.72)$ & 0.03 \\
\hline —with ECRS, n (\%) & $12(86)$ & $8(80)$ & $1.5(0.17-13)$ & 0.71 & $0.51(0.006-41)$ & 0.76 \\
\hline
\end{tabular}

Abbreviations: GETE Global Evaluation of Treatment Effectiveness, BMI body mass index, $b E O S$ peripheral blood eosinophil count at baseline, $b B A S O$ peripheral basophil count at baseline, FeNO fractional exhaled nitric oxide, ppb parts-per-billion, MEPO previous mepolizumab treatment, $A E R D$ aspirin-exacerbated respiratory disease, ECRS eosinophilic chronic rhinosinusitis

with specific IgE responses to staphylococcal enterotoxin A in AERD patients [34]. These findings indicate that anti-IgE antibody may be more effective than anti-IL-5/ IL-5RA antibody, or that the drug response to anti-IL-5/ IL-5RA antibody may be different in some patients with AERD. We need further data from patients with AERD receiving anti-IL-5/IL-5RA antibody treatment.

We showed that switching from mepolizumab to benralizumab tended to slightly improve the mean values of some parameters without significant differences, but three patients demonstrated a change in $\mathrm{FEV}_{1} \geq 200 \mathrm{ml}$. On the other hand, the number of exacerbations increased without a significant difference, and one patient with AERD was switched backed to mepolizumab (Additional file 1). Further investigation is needed to determine the proper use of these two biologics.

Several limitations to the present study exist. First, this was a small, single-center, retrospective study. However, since the number of patients who received benralizumab (Q8W) in the Japanese subgroup of the CALIMA trial was 15 , analyzing small-group studies such as these is also important. Thus, to further confirm the primary statistical measures, we reevaluated the results via post-hoc power analysis. Second, the duration of benralizumab treatment was short (mean 11.5 months, range 4-17 months). Although the SIROCCO trial [6], a representative clinical trial of benralizumab, showed the efficacy of benralizumab within 4 months and the GINA guideline [3] recommends assessing the efficacy of biologics at approximately 4 months, we speculate that further long-term observations are required not only to precisely evaluate the efficacy but also to elucidate response predictors in a real-life study including patients with diverse backgrounds. Third, in the present study, $46 \%$ of the patients switched therapies. However, we showed interesting results that were not found in previous RCTs following the switch from mepolizumab. As the future studies, prospective multicentered clinical trials with more cases are necessary to verify the present results.

\section{Conclusion}

Benralizumab treatment for patients with SEA showed a clinical efficacy of approximately $60 \%$ based on the GETE score and may significantly improve the $\mathrm{FEV}_{1}$ in some patients with previous mepolizumab treatment.

\section{Supplementary information}

Supplementary information accompanies this paper at https://doi.org/10. 1186/s12890-020-01248-x.

Additional file 1. Characteristics of 12 patients who received other biologics before benralizumab treatment

Additional file 2. Patients characteristics at baseline in four subgroup [male, female, AERD (-) and (+)]

Additional file 3 Fig. Changes in clinical parameters in the AERD (-) and $(+)$ groups. All results are expressed as individual data, and the boxes represent the median and interquartile ranges. The upper and lower whiskers represent the 90th and 10th percentiles, respectively. These data were analyzed with the Mann-Whitney $U$ test or the Wilcoxon signed rank test. A: No significant differences in ACT scores were found before and after treatment in each group (Wilcoxon signed rank test). However, a significant difference was found in ACT scores at baseline between the two groups ( $p=0.012$, Mann-Whitney $U$ test). ${ }^{\dagger} p$ values with sufficient power that were re-evaluated by a post-hoc power analysis. B: Significant differences in the $\% \mathrm{FEV}_{1}$ were found before and after treatment in the AERD (-) group ( $p=0.044$, Wilcoxon signed rank test). Furthermore, significant differences in the $\% \mathrm{FEV}_{1}$ at baseline and after treatment were identified between the two groups ( $p=0.028$ and $p=0.031$, respectively, Mann-Whitney $U$ test). P values without sufficient power that were reevaluated by a post-hoc power analysis. Abbreviations: ACT; Asthma Control Test, AERD; aspirin-exacerbated respiratory disease, $\% \mathrm{FEV}_{1} ; \%$ forced expiratory volume in $1 \mathrm{~s}$

\section{Abbreviations}

ACT: Asthma Control Test; AERD: Aspirin-exacerbated respiratory disease; BMI: Body mass index; CRSwNP: Chronic rhinosinusitis with nasal polyps; CS: Corticosteroid; ECRS: Eosinophilic chronic rhinosinusitis; GETE: Global 
Evaluation of Treatment Effectiveness; ICS: Inhaled corticosteroid; IL: Interleukin; LABA: Long-acting $\beta$-2 agonist; LAMA: Long-acting muscarinic antagonist; LTRA: Leukotriene receptor antagonist; RCT: Randomized control trial; SEA: Severe eosinophilic asthma

\section{Acknowledgments}

Not applicable.

\section{Authors' contributions}

TN and HM equally designed the study, performed the statistical analysis and wrote the manuscript. TN, HM, SN, KO, HU, MH, SM and TI contributed to data collection. TN, HM, HH, JA and KK interpreted the results. All authors read and approved the final manuscript.

\section{Funding}

None.

\section{Availability of data and materials}

The datasets used and/or analyzed during the current study are available from the corresponding author upon reasonable request.

\section{Ethics approval and consent to participate}

For this retrospective study, written informed consent from the participants was unavailable and unnecessary. The Ethical Committee of Jikei University School of Medicine stated that patient consent was not necessary for this retrospective study. We performed opt-out consent on the website of our hospital. This study was approved by the Ethical Committee [30-319 (9340)]. The director/administer of Jikei University Hospital granted us permission to access the medical records. The data used in this study was anonymized before its use.

\section{Consent for publication}

Not applicable.

\section{Competing interests}

The authors declare that they have no competing interests.

Received: 31 January 2020 Accepted: 28 July 2020

Published online: 03 August 2020

\section{References}

1. WHO. Global surveillance, prevention and control of chronic respiratory diseases: a comprehensive approach; 2007. p. 1-146. Available at http:// whalibdoc.who.int/publications/2007/9789241563468_eng.pdf?ua=1. Accessed 20 February 2018.

2. Hekking PPW, Wener RR, Amelink M, Zwinderman AH, Bouvy ML, Bel EH. The prevalence of severe refractory asthma. J Allergy Clin Immunol. 2015; 135:896-902.

3. GINA. GINA Difficult-To-Treat \& Severe Asthma in adolescent and adult patients Diagnosis and Management. 2019. https://ginasthma.org/ severeasthma/. Accessed 18 April 2019.

4. Global initiative for asthma: Asthma management and prevention, 2019 . 2019; 49. Accessed 21 Octorber 2019.

5. Inoue $\mathrm{H}$, Kozawa M, Milligan KL, Funakubo M, Igarashi A, Loefroth E. A retrospective cohort study evaluating healthcare resource utilization in patients with asthma in Japan npj. Prim Care Respir Med. 2019;29:13 https://doi.org/10.1038/s41533-019-0128-8

6. Bleecker ER, FitzGerald JM, Chanez P, Papi A, Weinstein SF, Barker P, et al. Efficacy and safety of benralizumab for patients with severe asthma uncontrolled with high-dosage inhaled corticosteroids and long-acting $\beta 2-$ agonists (SIROCCO): a randomised, multicentre, placebo-controlled phase 3 trial. Lancet. 2016;388:2115-27.

7. FitzGerald JM, Bleecker ER, Menzies-Gow A, Zangrilli JG, Hirsch I, Metcalfe P, et al. Predictors of enhanced response with benralizumab for patients with severe asthma: pooled analysis of the SIROCCO and CALIMA studies. Lancet Respir Med. 2018:6:51-64.

8. FitzGerald JM, Bleecker ER, Nair P, Korn S, Ohta K, Lommatzsch M, et al. Benralizumab, an anti-interleukin-5 receptor a monoclonal antibody, as addon treatment for patients with severe, uncontrolled, eosinophilic asthma (CALIMA): a randomised, double-blind, placebo-controlled phase 3 trial. Lancet. 2016;388:2128-41.
9. Nair P, Wenzel S, Rabe KF, Bourdin A, Lugogo NL, Kuna P, et al. Oral glucocorticoid-sparing effect of Benralizumab in severe asthma. N Engl J Med. 2017;376:2448-58.

10. Shimoda T, Odajima H, Okamasa A, Kawase M, Komatsubara M, Mayer B, et al. Efficacy and safety of mepolizumab in Japanese patients with severe eosinophilic asthma. Allergol Int. 2017;66:445-51.

11. Numata T, Nakayama K, Utsumi H, Kobayashi K, Yanagisawa H, Hashimoto $M$, et al. Efficacy of mepolizumab for patients with severe asthma and eosinophilic chronic rhinosinusitis. BMC Pulm Med. 2019;19(176):1-9.

12. Ohta K, Adachi M, Tohda $Y$, Kamei T, Kato M, Mark Fitzgerald J, et al. Efficacy and safety of benralizumab in Japanese patients with severe, uncontrolled eosinophilic asthma. Allergol Int. 2018;67:266-72.

13. Ichinose $M$, Sugiura $H$, Nagase $H$, Yamaguchi $M$, Inoue $H$, Sagara $H$, et al. Japanese guidelines for adult asthma 2017. Allergol Int. 2017;66:163-89.

14. Santanello NC, Zhang J, Seidenberg B, Reiss TF, Barber BL. What are minimal important changes for asthma measures in a clinical trial? Eur Respir J. 1999; 14:23-7.

15. Tepper RS, Wise RS, Covar R, Irvin CG, Kercsmar CM, Kraft M, et al. Asthma outcomes: pulmonary physiology. J Allergy Clin Immunol. 2012;129:S65-87.

16. Pertzov B, Avraham U, Osnat S, Dorit S, Dror R, Reuven KM. Efficacy and safety of mepolizumab in a real-world cohort of patients with severe eosinophilic asthma. J Asthma. 2019:1-6.

17. American Thoracic Society ERS. American Thoracic Society Documents ATS / ERS Recommendations for Standardized Procedures for the Online and Offline Measurement of Exhaled Lower Respiratory Nitric Oxide and Nasal Nitric Oxide, 2005. Am J Respir Crit Care Med. 2005:171:912-30.

18. Schatz M, Kosinski M, Yarlas AS, Hanlon J, Watson ME, Jhingran P, et al. The minimally important difference of the asthma control test. J Allergy Clin Immunol. 2009;124:719-23.

19. Zierau L, Walsted ES, Thomsen SF, Backer V. Response to omalizumab in patients with severe allergic asthma: a real-life study. Respir Med. 2017;131: 109-13.

20. Kanda Y. Investigation of the freely available easy-to-use software "EZR" for medical statistics. Bone Marrow Transplant. 2013;48:452-8.

21. Magnan A, Bourdin A, Prazma CM, Albers FC, Price RG, Yancey SW, et al Treatment response with mepolizumab in severe eosinophilic asthma patients with previous omalizumab treatment. Allergy. 2016;71:1335-44.

22. Harvey ES, Langton D, Katelaris C, Stevens S, Farah CS, Gillman A, et al. Mepolizumab effectiveness and identification of super-responders in severe asthma. Eur Respir J. 2020;55:1902420. https://doi.org/10.1183/13993003. 02420-2019.

23. Morales DR, Guthrie B, Lipworth BJ, Jackson C, Donnan PT, Santiago VH. NSAID-exacerbated respiratory disease: a meta-analysis evaluating prevalence, mean provocative dose of aspirin and increased asthma morbidity. Allergy. 2015;70:828-35.

24. Tuttle K, Buchheit K, Laidlaw T, Cahill K. A retrospective analysis of mepolizumab in subjects with aspirin-exacerbated respiratory disease. J Allergy Clin Immunol Pract. 2018;6:1045-7.

25. DuBuske L, Newbold P, Wu Y, Trudo F. Seasonal variability of exacerbations of severe, uncontrolled eosinophilic asthma and clinical benefits of benralizumab. Allergy Asthma Proc. 2018;39:345-9.

26. Bourdin A, Husereau D, Molinari N, Golam S, Siddiqui MK, Lindner L, et al. Matching-adjusted indirect comparison of benralizumab versus interleukin-5 inhibitors for the treatment of severe asthma: a systematic review. Eur Respir J. 2018;52:1801393.

27. Busse W, Chupp G, Nagase H, Albers FC, Doyle S, Shen Q, et al. Anti-IL-5 treatments in patients with severe asthma by blood eosinophil thresholds: indirect treatment comparison. J Allergy Clin Immunol. 2019;143:2336.

28. Ramonell RP, Iftikhar $\| \mathrm{H}$. Effect of anti-IL5, anti-\| $5 \mathrm{R}$, anti- $\| 13$ therapy on asthma exacerbations: a network meta-analysis. Lung. 2020;198:95-103. https://doi.org/10.1007/s00408-019-00310-8.

29. Hayashi H, Mitsui C, Nakatani E, Fukutomi Y, Kajiwara K, Watai K, et al. Omalizumab reduces cysteinyl leukotriene and 9a,11ß-prostaglandin F2 overproduction in aspirin-exacerbated respiratory disease. J Allergy Clin Immunol. 2016;137:1585-7 e4.

30. Taniguchi M, Mitsui C, Hayashi H, Ono E, Kajiwara K, Mita H, et al. Aspirinexacerbated respiratory disease (AERD): current understanding of AERD. Allergol Int. 2019;68:289-95.

31. Bleecker ER, Wechsler ME, FitzGerald JM, Menzies-Gow A, Wu Y, Hirsch I, et al. Baseline patient factor impact on the clinical efficacy of Benralizumab for severe asthma. Eur Respir J. 2018;52:1800936. 
32. Stevens WW, Peters AT, Hirsch AG, Nordberg CM, Schwartz BS, Mercer DG, et al. Clinical characteristics of patients with chronic Rhinosinusitis with nasal polyps, asthma, and aspirin-exacerbated respiratory disease. J Allergy Clin Immunol Pract. 2017:5:1061-70.

33. Stevens WW, Ocampo CJ, Berdnikovs S, Sakashita M, Mahdavinia M, Suh $\mathrm{L}$, et al. Cytokines in chronic rhinosinusitis role in eosinophilia and aspirin-exacerbated respiratory disease. Am J Respir Crit Care Med. 2015 192:682-94.

34. Losol P, Kim SH, Shin YS, Ye YM, Park HS. A genetic effect of IL-5 receptor a polymorphism in patients with aspirin-exacerbated respiratory disease. Exp Mol Med. 2013:45:e14.

\section{Publisher's Note}

Springer Nature remains neutral with regard to jurisdictional claims in published maps and institutional affiliations.

Ready to submit your research? Choose BMC and benefit from:

- fast, convenient online submission

- thorough peer review by experienced researchers in your field

- rapid publication on acceptance

- support for research data, including large and complex data types

- gold Open Access which fosters wider collaboration and increased citations

- maximum visibility for your research: over $100 \mathrm{M}$ website views per year

At BMC, research is always in progress.

Learn more biomedcentral.com/submissions 